\title{
Deflazacort Versus Prednisolone:Randomized Controlled Trial in Treatment of Children With Idiopathic Nephrotic Syndrome
}

\author{
Ravish Singhal ${ }^{1, *}$; Sadbhavna Pandit ${ }^{1}$; Neeraj Dhawan ${ }^{1}$ \\ ${ }^{1}$ Department of Pediatrics, Government Multispecialty Hospital, Chandigarh, India \\ *Corresponding author: Ravish Singhal, Department of Pediatrics, Government Multispecialty Hospital, Chandigarh, India. Tel: +91-9855200125, E-mail: ravish_singhal@yahoo.com
}

Received: February 8, 2015; Revised: February 15, 2015; Accepted: March 10, 2015

\begin{abstract}
Background: Corticosteroids are the main therapy of nephrotic syndrome and goal of corticosteroid therapy is to obtain maximum clinical benefit with minimum adverse effects. Children are more vulnerable to side effects of corticosteroids related to growth and adrenal suppression, so a search for an alternative steroid with fewer side-effects is underway. Deflazacort is an oxazoline derivative and preliminary data suggest reduced osteoporosis, lesser growth retardation and weight gain with deflazacort.

Objectives: This study was done to compare the effectiveness and safety of deflazacort in idiopathic nephrotic syndrome.

Patients and Methods: Twenty five children with age between 2 to 12 years, with idiopathic nephrotic syndrome were enrolled. They were randomly assigned to receive deflazacort (Group $A, n=12$ ) or prednisolone (Group B, $n=13$ ) and were followed up for six months.

Results: All children of group A and 11 of group B had remission. Two children from group B were steroid resistant. Mean time taken to induce remission was significantly $(\mathrm{P}=0.012)$ less in group $\mathrm{A}(10.25 \pm 2.41$ days $)$ than group $\mathrm{B}(12.55 \pm 1.44$ days $)$. One patient in group $\mathrm{A}$ had relapse on follow up as compared to 3 in group $B(P=0.58)$. Statistically significant difference $(P=0.03)$ in change in mean height was found between group $A(2.13 \pm 0.50 \mathrm{~cm})$ and $B(1.44 \pm 0.45 \mathrm{~cm})$, with group $B$ gaining less height.

Conclusions: Remission rate in both groups was comparable although time taken to induce remission was shorter in deflazacort group and there was a significant difference in change of mean height on follow up with prednisolone group gaining lesser height.
\end{abstract}

Keywords: Prednisolone; Nephrotic Syndrome; Kidney

\section{Background}

Nephrotic syndrome is characterized by heavy proteinuria, hypoalbuminemia (serum albumin $<2.5 \mathrm{~g} / \mathrm{dL}$ ), hyperlipidemia (serum cholesterol $>200 \mathrm{mg} / \mathrm{dL}$ ) and edema (1). Estimates on the annual incidence of nephrotic syndrome range from $2-7 / 100,000$ children, and prevalence from $12-16 / 100,000$ (2). The condition is primary (idiopathic) in $95 \%$ cases. An underlying disorder that might be identified in $<5 \%$ cases, includes systemic lupus erythematosus, Henoch Schönlein purpura, amyloidosis and infection with HIV, Parvovirus B19 and Hepatitis $B$ and $C$ viruses $(3,4)$. More than $80 \%$ patients with nephrotic syndrome show minimal change disease (MCD) characterized by normal renal histology on light microscopy. The remaining is contributed by focal segmental glomerulosclerosis (FSGS) and mesangioproliferative glomerulonephritis (MesPGN) (5).

Conventionally, after the diagnosis of nephrotic syndrome is confirmed by appropriate laboratory studies and associated infection (if any) has been treated, the patient is put on corticosteroids (prednisolone). The time needed for steroid response averages 2 weeks, response being defined as the point at which urine becomes protein free for 3 consecutive days (6). The International Study for Kidney Diseases in Children had originally rec- ommended a regimen comprising of four-weeks each of daily and alternate day steroid therapy which was used for almost three decades. Controlled studies later suggested that prolongation of initial steroid therapy for 12 weeks or longer are associated with significantly reduced risk for subsequent relapses. However, prolonged treatment is associated with a higher frequency of adverse events (7-9).

Based on current evidence and opinion, the Group recommends that the initial episode of nephrotic syndrome be treated with prednisolone at a dose of $2 \mathrm{mg} / \mathrm{kg} / \mathrm{day}$ (maximum $60 \mathrm{mg}$ in single or divided doses) for 6 weeks, followed by $1.5 \mathrm{mg} / \mathrm{kg}$ (maximum $40 \mathrm{mg}$ ) as a single morning dose on alternate days for the next 6 weeks (10), therapy is then discontinued.

Anti-inflammatory effects are inseparable from metabolic effects, the goal of corticosteroid therapy is to obtain maximum clinical benefit with minimum adverse effects. Since children are more vulnerable to side effects of corticosteroids related to growth and adrenal suppression, a search for an alternative oral steroid with fewer side-effects is underway throughout the world. Deflazacort is a D-ring substituted steroid (11), otherwise similar to cortisol having molecular formula 1,1 beta, 21

Copyright (C) 2015, Growth \& Development Research Center. This is an open-access article distributed under the terms of the Creative Commons Attribution-NonCommercial 4.0 International License (http://creativecommons.org/licenses/by-nc/4.0/) which permits copy and redistribute the material just in noncommercial usages, provided the original work is properly cited. 
- dihydroxy- 2 - methyl- 5 - beta- 11 - pregnan - 1, 4 dieno oxazole - 3, 20 - dione - 21 acetate. Preliminary data suggest reduced osteoporosis, lesser growth retardation and weight gain with deflazacort. This study was taken up to compare the effectiveness and safety of deflazacort in children with idiopathic nephrotic syndrome in a prospective open labeled randomized controlled trial.

\section{Objectives}

Primary objectives were studied as time taken to induce remission, remission rate, number of relapses on and off drugs in both groups. Secondary objectives were mean weight gain, mean weight-height ratio, development of cushingoid symptoms, hypertension and posterior capsular opacity and steroid resistance rate in both the groups.

\section{Patients and Methods}

A total of 25 consecutive children aged 2 - 12 years presenting with idiopathic nephrotic syndrome (1st episode or infrequent relapser) in Paediatrics OPD and Ward of GMSH- 16, Chandigarh were studied. Cases of acute glomerulonephritis, cases $<2$ years and $>12$ years of age and which presented with triad of hypertension, hematuria, azotemia and steroid resistant/dependant/frequent relapser nephrotic syndrome cases (earlier diagnosed) and those with secondary nephrotic syndrome due to any systemic disorder or drug agent were excluded. On entry into the study a detailed history was taken and physical examination done to rule out any likely cause of secondary nephrotic syndrome and infection. Routine investigations such as complete blood count, urine routine examination and culture, renal function tests, serum cholesterol, electrolytes, X-ray chest, Mantoux test and Australian antigen were done.

Eye examination was done by the ophthalmologist with slit lamp. Cushingoid features were evaluated by the investigator based on assessment of face and trunk at the start of study and follow up. Urine output was measured in calibrated plastic bottle. The project was approved by Hospital Ethics Committee and informed consent was taken from patients or guardians. The trial was registered at Clinical Trial Registry of India, New Delhi vide no. 2011/11/002927.

\subsection{Randomization}

The patients were randomly allocated to either group $\mathrm{A}$ (DFZ) or group B (PDN) on the basis of computer generated random number table system. During study period a patient once enrolled was not enrolled again in case of relapse and was provided the same drug as used earlier.

\subsection{Dosage Equivalence}

Based on previous bioequivalence studies and as per drug information leaflet of the drug formulations used, anti inflammatory and immunosuppressive potency of deflazacort is 0.8 times that of prednisolone.

\subsection{Group $A$}

Patients received deflazacort. First Attack: Dose of deflazacort $2.4 \mathrm{mg} / \mathrm{kg} /$ day daily for 6 weeks (two or three divided doses). Then $1.8 \mathrm{mg} / \mathrm{kg} /$ alternate day for 6 weeks (single dose). Relapse: Dose of deflazacort $2.4 \mathrm{mg} / \mathrm{kg} /$ day (two or three divided doses) till urine was albumin free/ traces for 3 consecutive days. Then $1.8 \mathrm{mg} / \mathrm{kg} /$ alternate day (single dose for 4 weeks).

\subsection{Group B}

Patients received prednisolone. First Attack: Dose of prednisolone $2.0 \mathrm{mg} / \mathrm{kg} /$ day daily for 6 weeks (two or three divided doses). Then $1.5 \mathrm{mg} / \mathrm{kg} /$ alternate day for 6 weeks (single dose). Relapse: Dose of prednisolone 2.0 $\mathrm{mg} / \mathrm{kg} /$ day (single dose OD) till urine was albumin free/ traces for 3 consecutive days. Then $1.5 \mathrm{mg} / \mathrm{kg} /$ alternate day (single dose for 4 weeks).

Definitions

Relapse: Urinary protein excretion $>40 \mathrm{mg} / \mathrm{m}^{2} /$ hours; or $\geq 3+$ dipstick for 3 consecutive days with or without edema.

Remission: Urinary protein excretion $<4 \mathrm{mg} / \mathrm{m}^{2} /$ hours; nil or trace by dipstick on spot sample for 3 consecutive days.

Frequent relapses: Two or more relapses in 6 months of initial response; 4 or more relapses in any 12 months period.

Steroid dependence: Occurrence of 2 consecutive relapses during steroid therapy or within 2 week of its cessation.

Steroid resistance: Failure to achieve remission after 4 week of daily therapy with oral prednisone at a dose of 2 $\mathrm{mg} / \mathrm{kg} /$ day.

Urine albumin was done daily till it was albumin free/ traces for 3 consecutive days. This was taken as onset of remission (dipstick method). It was repeated if any symptoms as pedal edema or fever occurred during or after treatment. Urine routine examinations were done monthly till the continuation of steroid therapy and for next 6 months of follow up or earlier if any symptoms like swelling or edema appeared. Height, weight, BP, cushingoid facies, eye examination was done at the time of enrollment and then monthly during treatment and subsequently during follow up for next 6 months after stopping steroids. To prevent defaulters and to assure compliance the patients were asked to bring back empty tablet blisters or syrup bottles.

\subsection{Sample Size}

With an estimated hospital OPD and admission rate of approximately 22 children (according to an unpublished statistical data of year 2008 of this institution) that have idiopathic nephrotic syndrome and a calculated dropout rate of $10 \%, 25$ children were enrolled for the study. 


\subsection{Statistical Analysis}

Discrete categorical data was presented as n (\%); continuous data was given as Mean $\pm \mathrm{SD}$, median and interquartile range, as appropriate. Mann-Whitney U-test was used for statistical analysis of skewed continuous variables and ordered categorical variables. For normally distributed data t-test was applied. For categorical data comparisons were made by Pearson Chi-square test and Fisher's exact test as appropriate. All statistical tests were twosided and performed at a significance level of $\mathrm{P}=0.05$. All analyses were conducted using SPSS for Windows (version 15.0; SPSS Inc., Chicago, IL, USA).

\section{Results}

A total of 25 consecutive children, with age varying from 2 to 12 years, presenting in their initial or subsequent episode with idiopathic nephrotic syndrome in Outpatient and Emergency Department of Government MultiSpecialty Hospital, Sector- 16, Chandigarh were enrolled in the study during the period starting from March, 2011. Of the 25 patients, 12 were randomized to group A and 13 to group B by computer generated random number table to receive deflazacort and prednisolone respectively. In group A, 1 patient was lost to follow up after remission (Figure 1).

Patients in group A and group B were comparable with respect to demographic data, clinical profile and baseline investigations as age, sex ratio, anthropometry, edema, ascites, blood pressure, blood urea, serum creatinine, serum proteins, fasting blood sugar and serum cholesterol (Table 1). Ten children out of total of 25 enrolled in the study were relapsers. In group A, there were 3 children with first relapse and 2 children with 2 nd relapse. In group B, there were 3 children with first relapse and 2 children with 3 rd relapse. This difference between two groups was statistically insignificant $(P=0.13)$. None of the cases in both groups had earlier received any other immunosuppressive like cyclophosphamide, mycophenolate moeftil, calcineurin inhibitors etc.

\subsection{Primary Outcome}

Mean time taken to induce remission was $10.25 \pm 2.41$ days and $12.55 \pm 1.44$ days in group A and B respectively (Table 2). Time to induce remission was shorter in deflazacort group as compared to prednisolone group and this difference was statistically significant $(P=0.012)$. With a mean difference in remission time of 2.3 days and SD of 1.92 , power of our study was $86 \%$ with a confidence interval of $95 \%$.

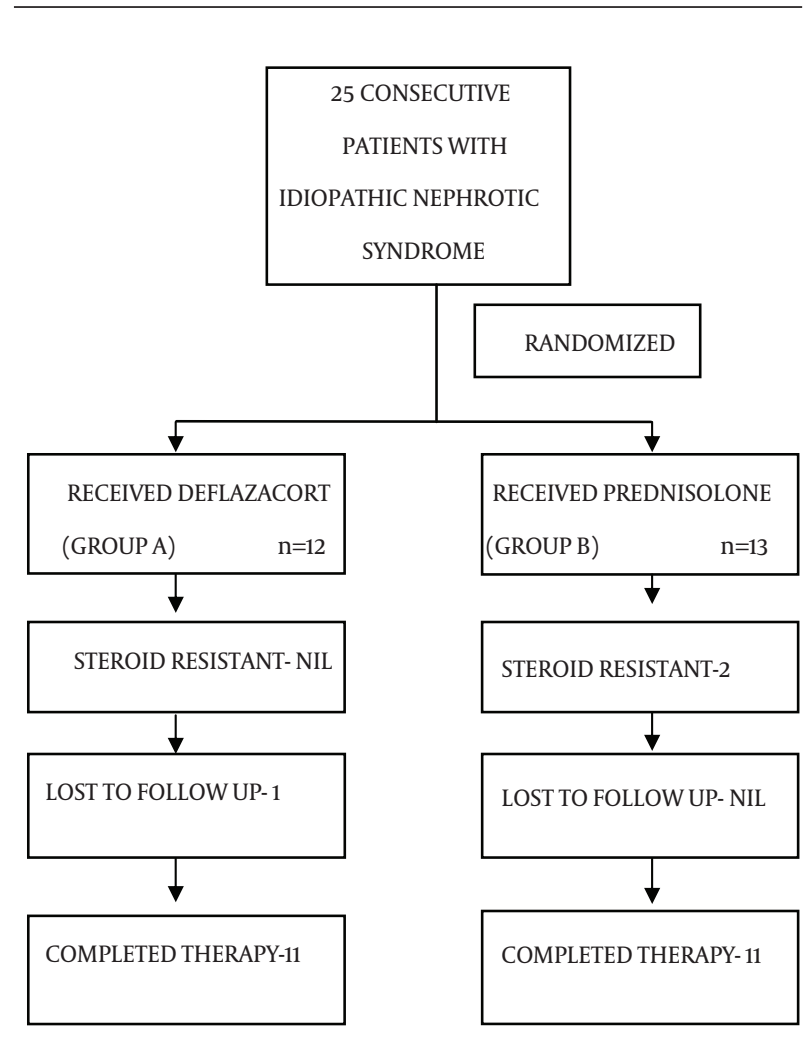

Figure 1. Trial Profile Showing Division in Both the Groups

\begin{tabular}{|c|c|c|c|c|}
\hline S No. & Parameter & Group A DFZ ${ }^{\text {b }}$ & Group B PDN C & PValue \\
\hline 1. & Age, y & $3.54 \pm 1.21$ & $5.53 \pm 3.73$ & 0.091 \\
\hline 2. & Gender, males & $7(58.3 \%)$ & $7(53.8 \%)$ & 0.821 \\
\hline 3. & Weight, kg & $14.21 \pm 3.28$ & $17.94 \pm 10.03$ & 0.232 \\
\hline 4. & Height, cm & $93.87 \pm 8.79$ & $102.80 \pm 23.66$ & 0.231 \\
\hline 5. & Weight/Height ratio, kg/cm & $0.15 \pm 0.02$ & $0.16 \pm 0.05$ & 0.437 \\
\hline 6. & S. Protein, gm/L & $5.44 \pm 1.30$ & $5.06 \pm 1.25$ & 0.46 \\
\hline 7. & S. Albumin, gm/L & $2.85 \pm 0.97$ & $2.79 \pm 0.81$ & 0.85 \\
\hline 8. & S. Cholesterol (mg/dL) & $320.41 \pm 44.97$ & $266.53 \pm 88.52$ & 0.07 \\
\hline
\end{tabular}


Singhal R et al.

\begin{tabular}{|c|c|c|c|c|}
\hline S No. & Outcome Parameter & Group A DFZ ${ }^{\text {b }}$ & Group B PDN ${ }^{\mathrm{C}}$ & P Value \\
\hline 1. & Remission rate & $12(100 \%)$ & $11(84.6 \%)$ & 0.480 \\
\hline 2. & Time to induce remission, days & $10.25 \pm 2.4$ & $12.55 \pm 1.44$ & 0.012 \\
\hline 3. & No. of relapses on follow up & $1(9.1 \%)$ & $3(27.3 \%)$ & 0.586 \\
\hline 4. & Change in weight, kg & $1.36 \pm 0.96$ & $1.38 \pm 0.56$ & 0.958 \\
\hline 5. & Change in height, $\mathrm{cm}$ & $2.13 \pm 0.50$ & $1.44 \pm 0.45$ & 0.003 \\
\hline 6. & Change in weight/height ratio & $0.01 \pm 0.010$ & $0.01 \pm 0.006$ & 0.931 \\
\hline
\end{tabular}

Twenty three (92\%) children, of which all 12 from group A and 11 from group B enrolled in the study, had remission. In group B, 2 patients with first attack were found to be steroid resistant. There was no significant difference found between group A and B in relation to remission rate $(\mathrm{P}=0.48)$. Out of a total 22 children who completed study period, $5(22.7 \%)$ had relapse. In group A, 1 child had relapse on treatment precipitated by meningitis and 1 child had relapse during follow up of 6 months. In group B, 3 children had relapse during follow up period of 6 months. Though the number of relapses on follow up was more in case of group B but this difference was not statistically significant. Relative risk of relapse on follow up in group A as compared to group B was 0.33 with 95\% confidence interval ranging from 0.04 to 2.73 .

\subsection{Secondary Outcome}

The secondary outcome that was mean weight gain was higher in prednisolone group $(1.38 \pm 0.56 \mathrm{~kg})$ as compared to deflazacort $(1.36 \pm 0.96 \mathrm{~kg})$ but was not statistically significant $(\mathrm{P}=0.95)$. Numbers of children who developed cushingoid features at the end of treatment and follow up were more in group B. But this difference was not statistically significant. Number of children with hypertension at start of study and at end of treatment and follow up was not different in two groups. No child in the study had posterior lenticular opacity and neither developed it during treatment and follow up. Steroid resistance was present only in prednisolone group (15.3\%) but this difference was statistically non-significant $(P=0.48)$. All the patients in the study were euglycemic at the beginning, and remained so till the end of treatment and follow up.

\section{Discussion}

In view of the limited data demonstrating superiority of deflazacort over the available oral steroids this study was taken up to compare the effectiveness and safety of deflazacort in children with idiopathic nephrotic syndrome. Broyer et al. (12) have concluded that DFZ was more effective than PDN in limiting relapses in steroid dependent idiopathic nephrotic syndrome.

This study has demonstrated that time to induce remis- sion was shorter in deflazacort group as compared to prednisolone group and this difference was statistically significant $(\mathrm{P}=0.012)$. Thus deflazacort induces earlier remission in patients with steroid sensitive idiopathic nephrotic syndrome.

Twenty three (92\%) children, of which all 12 from group A and 11 from group B enrolled in the study, had remission. There was no significant difference found between group $A$ and $B$ in relation to remission rate $(P=0.48)$. In study by Broyer et al. (12) all the children had remission, no child became steroid resistant. The number of relapses on follow up was more in case of group B but this difference was not statistically significant. So it can be concluded that deflazacort is equipotent with prednisolone in inducing remission and preventing relapses.

Mean weight gain was higher in prednisolone group $(1.38 \pm 0.56 \mathrm{~kg})$ as compared to deflazacort (1.36 \pm 0.96 $\mathrm{kg}$ ) but was not statistically significant $(\mathrm{P}=0.95)$. Broyer et al. (12) too have reported higher mean weight gain in prednisolone group $(3.9 \pm 4.1 \mathrm{~kg})$ but the difference from deflazacort group $(1.7 \pm 2.8 \mathrm{~kg})$ was not significant. Mean height increase in case of deflazacort $(2.13 \pm 0.50 \mathrm{~cm})$ was more as compared to prednisolone $(1.44 \pm 0.45 \mathrm{~cm})$ and difference was significant statistically $(\mathrm{P}=0.03)$. Broyer et al. (12) have reported significantly higher body height standard deviation score in prednisolone group at start of the study but no significant difference at end of the study. As the patients of prednisolone group had a greater decrease in mean standard deviation score, which is interpreted as a greater adverse effect of prednisolone on growth than deflazacort.

Numbers of children who developed cushingoid features at the end of treatment and follow up were more in group B. But this difference was not statistically significant. Broyer et al. (12) too showed a tendency for fewer side effects in deflazacort group but this difference was found to be insignificant by them. Number of children with hypertension at start of study and at end of treatment and follow up was not different in two groups. No child in the study had posterior lenticular opacity and neither developed it during treatment and follow up. Steroid resistance was present only in prednisolone group (15.3\%) but this difference was statistically non-significant 
$(\mathrm{P}=0.48)$. All the patients in the study were euglycemic at the beginning, and remained so, at the end of treatment and follow up. The limitation of our study is non-blinded study design and short follow-up, it should have been of longer duration to study various metabolic side effects of prednisolone over deflazacort that may develop later on and in subsequent relapses.

We conclude that deflazacort in equipotent doses to prednisolone was effective in the treatment of children with idiopathic nephrotic syndrome. Remission rate in both groups was comparable although time taken to induce remission was shorter in deflazacort group. Relapse rate on follow up was not significantly different between deflazacort and prednisolone group. No significant difference in cushingoid features, fasting blood sugar, blood pressure was found in two groups. There was significant difference in change of mean height on follow up with prednisolone group gaining lesser height than deflazacort group. Remission rate in eflazacort and prednisolone groups was comparable although time taken to induce remission was shorter in deflazacort group and there was a significant difference in change of mean height on follow up with prednisolone group gaining lesser height.

\section{Acknowledgements}

We thank Dr. Harmesh Singh Bains, Head of department, Paediatrics, DMCH, Ludhiana who has analyzed this paper carefully and extended his valuable suggestions.

\section{Author's Contributions}

Ravish Singhal: concept and design, acquisition of data, data analysis. Sadbhavna Pandit: Data analysis and criti- cal revision of the manuscript. Neeraj Dhawan: Drafting of manuscript and data analysis.

\section{References}

1. Consensus statement on management of steroid sensitive nephrotic syndrome. Indian Pediatric Nephrology Group IAOP. Indian Pediatr. 2001;38(9):975.

2. Nephrotic syndrome in childhood. Eddy AA, Symons JM. Lancet. 2003;362(9384):629.

3. Bagga A, Srivastava RN. Pediatric Nephrology. 4th ed. New Delhi: Jaypee; 2005. Nephrotic syndrome. pp. 159-200.

4. Association of parvovirus B19 infection with idiopathic collapsing glomerulopathy. Moudgil A, Nast CC, Bagga A, Wei L, Nurmamet A, Cohen AH, et al. Kidney Int. 2001;59(6):2126.

5. Nephrotic syndrome in children. Bagga A, Mantan M. Indian J Med Res. 2005;122(1):13.

6. Pais P. Nephrotic Syndrome. In: Nelson WE, Behrman RE, Kleig man RH, Aruin AM, editors. Nelson Textbook of Pediatrics. 19th ed. Philadelphia: Saunders; 2011. pp. 1801-4.

7. Primary nephrotic syndrome in children: clinical significance of histopathologic variants of minimal change and of diffuse mesangial hypercellularity. A Report of the International Study of Kidney Disease in Children. Kidney Int. 1981;20(6):765.

8. Evaluation and management of proteinuria and nephrotic syndrome in children. Recommendations from a Pediatric Nephrology Panel established at the National Kidney Foundation Conference on proteinuria, albuminuria risk, assessment, detection and elimination (PARADE). Hagg R, Portman RJ, Milliner D. Pediatrics. 2000;106:1242-9.

9. Prolonged versus standard prednisolone therapy for initial episode of nephrotic syndrome. Bagga A, Hari P, Srivastava RN. Pediatr Nephrol.1999;13(9):824.

10. Management of steroid sensitive nephrotic syndrome: revised guidelines. Indian Pediatric Nephrology Group IAOP, Bagga A, Ali U, Banerjee S, Kanitkar M, Phadke KD, et al. Indian Pediatr. 2008;45(3):203.

11. Deflazacort versus other glucocorticoids: a comparison. Nayak $\mathrm{S}$, Acharjya B. Indian J Dermatol. 2008;53(4):167.

12. A controlled study of deflazacort in the treatment of idiopathic nephrotic syndrome. Broyer M, Terzi F, Lehnert A, Gagnadoux MF, Guest G, Niaudet P. Pediatr Nephrol. 1997;11(4):418. 